\title{
Evaluation Model and Simulation of High Efficient Toll Plaza
}

\author{
Zhidan Cai ${ }^{*}$, Juewei Hu, Xiaoyu Liu and Xin Li \\ School of Science, Changchun University of Science and Technology, China \\ *Corresponding author
}

\begin{abstract}
In this paper, we mainly discuss the design and evaluate of how the vehicle return to the original line after passing the toll station. In the case of considering only one direction of the toll square, we establish the evaluation model based on the cellular automata. In the meantime, we emphasis on the probability of accidents and exclude the influence of subjective factors. In view of the physical truth, we change the shape of the toll booth, we distinguish the speed of car based on the original evaluation methodology in order to reduce the cost and the rate of accident.Finally, we come to the conclusion that the improvement toll station is superior to the original one according to the performance appraisal.
\end{abstract}

Keywords-evaluation model; traffic flow; cellular automata

\section{INTRODUCTION}

In order to indicate the origin of the toll way problems, the following background is worth mentioning. In this thesis, we mainly discuss the problem of returning to the original lane after being charged on the expressway. Namely, when there are $\mathrm{L}$ lanes in each direction of the expressway and $\mathrm{B}$ toll booths at the toll booths $(\mathrm{B}>\mathrm{L})$, how can people design the most reasonable toll plaza? Thus, we consider establishing the model of toll plaza evaluation, which includes factors such as the probability of accidents, the number of vehicles traveling from the toll area to the $\mathrm{L}$ lanes per hour, and the cost of land and the road construction. Therefore, the main point is to find a way to measure the probability of accidents, quantify the cost of land and road construction, and to build an evaluation model based on the factors all above.

\section{Evaluation Model OF TOll PlazA}

As mentioned above, in order to measure the reasonableness of the toll plaza, we should establish an evaluation model of the toll plaza. Based on the bidirectional of the highway traffic and the assumption, we can know that the two-way toll area model is the same [1]. So in this thesis, only unidirectional channel is considered on the establishment of the toll plaza evaluation model [2]. This section will focus on three factors, the accident rate, the amount of access, and the cost, which is used to establish a toll plaza evaluation model [3]. As the dimensional of accident rate $N$ the amount of $Q$, and the area of $A$ are different, the direct calculation for the weighted average value is of no mathematical significance.

\section{SimUlation AND RESUlt ANALYSIS}

Most existing toll booths are shaped like a right-angle trapezoid, more toll booths on the right angle trapezoidal high and oblique shape have some changes. Considering the influence on these two factors is reasonable. The result can be shown as the following:

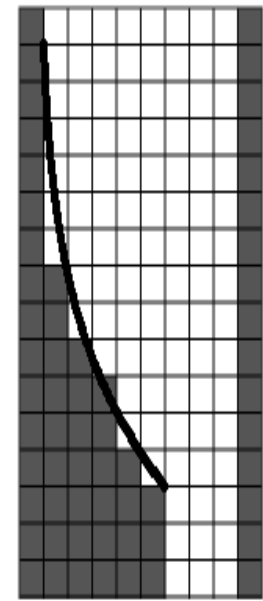

FIGURE I.

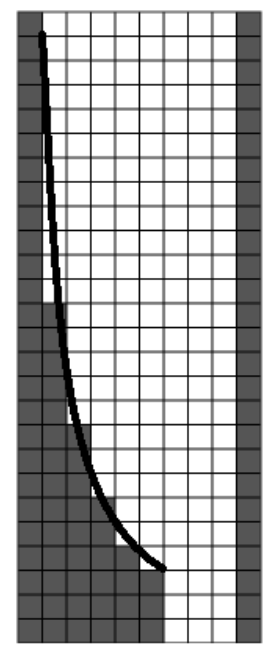

FIGURE II.

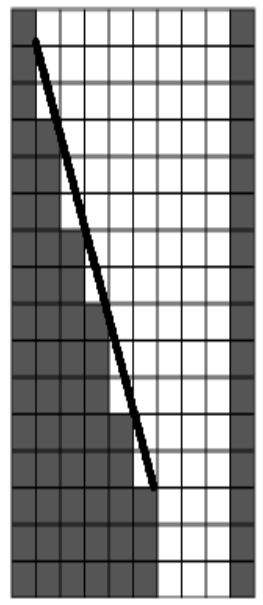

SHORT TOOL STATION

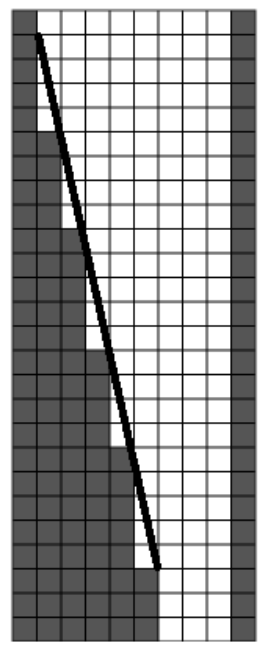

LONG TOOL STATION
The figure includes four types of toll plazas. In addition, because the boundary of the actual toll station is continuous, it 
is necessary to discretize the continuous boundary after abstracting the toll station into cellular network. If the boundary area is greater than half of the area of a single cell, it means that the car can pass through the boundary, that is, the cell belongs to the toll plaza, otherwise the cell belongs to the boundary.

Considering the shape of the existing charging square deformation, the shape of the toll plaza is designed to be similar to the shape of the isosceles trapezoid. As the figure shows below:
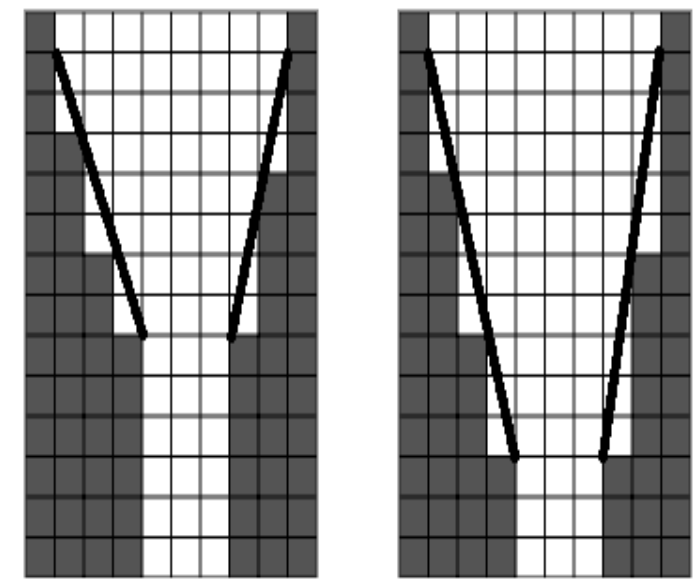

FIGURE III.

IMPROVEMENT TOLL STATION

Considering the different merge modes, there are limitations on the regular lanes. The direction of the provisions of the lane to the left of the fast lane, only car into. The middle lane for the ordinary lane, only car into. The right lane is a slow lane; all the vehicles can enter. Simultaneously, we assume that some drives may have an emergence or they do not follow the traffic rules, the lane in the cart and car is set as follows:

TABLE I. THE PROPORTION OF VEHICLES IN DIFFERENT LANE

\begin{tabular}{ccc}
\hline Drive Type & $\begin{array}{c}\text { Proportion of } \\
\text { cars }\end{array}$ & $\begin{array}{c}\text { Proportion of } \\
\text { carts }\end{array}$ \\
\hline Fast lane & $45 \%$ & $1 \%$ \\
Ordinary lane & $45 \%$ & $9 \%$ \\
Slow lane & $10 \%$ & $90 \%$ \\
\hline
\end{tabular}

\section{Simulation Results}

This section will be based on the parameters gaining from different toll plazas and different cellular automaton simulations. The index number of the number of change lanes $N$, the quantity $Q$ of entrance, and the area $A$ in the evaluation system are obtained.

Due to the stochastic characteristic of cellular automata, the method of running multiple times and averaging the results is adopted. Each time we take the number of runs to 1000 . For each toll plaza, we use the average of the indicator data after 100times as the final indicator value. The conventional toll plaza index values are as follows:
TABLE II. TOLL PLAZA INDEX VALUES

\begin{tabular}{|c|c|c|c|c|c|c|c|c|}
\hline \multirow{2}{*}{$\begin{array}{l}\text { N } \\
\text { o. }\end{array}$} & $\begin{array}{l}\text { Leng } \\
\text { th }\end{array}$ & \multicolumn{2}{|c|}{$\begin{array}{l}\text { Boundar } \\
\text { y Shape }\end{array}$} & \multicolumn{2}{|c|}{ Merge Mode } & \multicolumn{3}{|c|}{ Index Value } \\
\hline & S L & C & $\mathbf{R}$ & Lane & $\begin{array}{c}\text { No } \\
\text {-Lane }\end{array}$ & $\mathbf{L}$ & C & $\mathbf{R}$ \\
\hline 1 & - $\quad-$ & • & - & • & - & 1375 & 594 & 80 \\
\hline 2 & - - & • & - & - & • & 1679 & 590 & 80 \\
\hline 3 & - $\quad-$ & - & - & - & - & 1718 & 590 & 70 \\
\hline 4 & - $\quad-$ & - & - & - & - & 1694 & 592 & 70 \\
\hline 5 & $-\quad \cdot$ & • & - & • & - & 1725 & 591 & $\begin{array}{c}15 \\
3\end{array}$ \\
\hline 6 & $-\quad \cdot$ & - & - & - & • & 1699 & 591 & $\begin{array}{c}15 \\
3\end{array}$ \\
\hline 7 & - & - & - & - & - & 1720 & 591 & $\begin{array}{c}12 \\
8\end{array}$ \\
\hline 8 & $-\quad \cdot$ & - & • & - & • & 1688 & 589 & $\begin{array}{c}12 \\
8\end{array}$ \\
\hline 9 & - $\quad-$ & - & - & • & - & 1265 & 591 & 43 \\
\hline $\begin{array}{l}1 \\
0\end{array}$ & • - & - & - & - & • & 1267 & 589 & 43 \\
\hline $\begin{array}{l}1 \\
1\end{array}$ & $-\quad \cdot$ & - & - & • & - & 1255 & 586 & 63 \\
\hline $\begin{array}{l}1 \\
2\end{array}$ & - & - & - & - & - & 1258 & 583 & 63 \\
\hline
\end{tabular}

Note: - Indicates that the toll plaza has this attribute, - indicates that the toll plaza does not have this attribute. For example, the toll plaza numbered 1 is a short-concave-lane toll station.

\section{Performance Ranking of Toll Plaza}

According to the simulation results above and weight values, the rank of different toll plaza performance are listed as follows:

TABLE III. TOLL PLAZA RANK

\begin{tabular}{c|ccc|c}
\hline \multirow{2}{*}{$\mathbf{N}$} & \multicolumn{3}{|c|}{ Index Value } & \multirow{2}{*}{ Rank } \\
\cline { 2 - 4 } $\mathbf{0 .}$ & $\mathbf{N}$ & $\mathbf{Q}$ & $\mathbf{A}$ & \\
\hline 1 & 1716 & 589 & 81 & 0.730 \\
2 & 1693 & 593 & 81 & 0.511 \\
3 & 1718 & 594 & 70 & 0.633 \\
4 & 1694 & 592 & 70 & 0.592 \\
5 & 1725 & 591 & 153 & 0.159 \\
6 & 1699 & 591 & 153 & 0.162 \\
7 & 1720 & 591 & 128 & 0.276 \\
8 & 1688 & 589 & 128 & 0.262 \\
9 & 1265 & 591 & 43 & 0.911 \\
10 & 1267 & 589 & 43 & 0.877 \\
11 & 1255 & 586 & 63 & 0.719 \\
12 & 1258 & 583 & 63 & 0.66 \\
\hline
\end{tabular}

TABLE IV. MODEL VERIFICATION

\begin{tabular}{cccccc}
\hline $\begin{array}{c}\text { Types of toll } \\
\text { plazas }\end{array}$ & B & L & N & Q & A \\
\hline Conventional & 5 & 2 & 775.4 & 442.6 & 31.0 \\
Improvement & 5 & 2 & 636.9 & 440.6 & 31.0 \\
Conventional & 10 & 4 & 2074.0 & 600.6 & 111.0 \\
Improvement & 10 & 4 & 1537.8 & 598.6 & 80.0 \\
\hline
\end{tabular}


It is obviously from the table that the conventional toll plaza and the improved toll plaza access is more similar to the improved toll square area value, and the number of lanes were less than the conventional toll plaza. It is shown that the modified toll plaza is superior to the conventional toll plaza in the case of $\mathrm{B}=5, \mathrm{~L}=2$ and $\mathrm{B}=10$ and $\mathrm{L}=4$.

\section{CONCLUSION}

This paper set up the toll plaza evaluation model based on a large number of simulation data, analog cellular automata is the possibility of randomness. At the same time, we use the method of maximizing deviations. By giving weights of different factors, we can avoid the influence of subjective factors in determining the weight.

In this paper, we improved the factors that reduce the incidence and the cost of accidents while guarantee the regular operation of toll booths. The improved outcome has good adaptability to different toll stations and conventional lines.

\section{REFERENCES}

[1] Chowdhary M. Vehicle safety management system that detects frequent lane change violations: U.S. Patent Application 10/788,675[P]. 2004-227.

[2] Tanimoto J, Fujiki T, Wang Z, et al. Dangerous drivers foster social dilemma structures hidden behind a traffic flow with lane changes[J]. Journal of Statistical Mechanics: Theory and Experiment, 2014, 2014(11): P11027.

[3] Cooper J M, Vladisavljevic I, Medeiros-Ward N, et al. An investigation of driver distraction near the tipping point of traffic flow stability[J]. Human factors, 2009, 51(2): 261-268. 